\title{
Correction to: Metoclopramide role in preventing ileus after cesarean, a clinical trial
}

\author{
Jila Agah $^{1} \cdot$ Roya Baghani $^{2} \cdot$ Mohammad Hassan Rakhshani $^{3} \cdot$ Abolfazl Rad $^{4}$
}

Published online: 16 November 2017

(C) Springer-Verlag GmbH Germany, part of Springer Nature 2017

Correction to: Eur J Clin Pharmacol (2015) 71:657-662

https://doi.org/10.1007/s00228-015-1845-8

The original publication of this paper contains an error.

The last 2 rows of Table 2 should read:

\begin{tabular}{llll}
\hline Characteristics & Metoclopramide & control & p-value \\
\hline First feeding & $544.2 \pm 107.7$ & $588.1 \pm 120.1$ & 0.000 \\
First ambulation & $574.9 \pm 126.7$ & $630.7 \pm 145.0$ & 0.000 \\
\hline
\end{tabular}

The online version of the original article can be found at https://doi.org/ $10.1007 / \mathrm{s} 00228-015-1845-8$

Jila Agah

jilaagah@yahoo.com

Roya Baghani

ry.baghany@yahoo.com

Mohammad Hassan Rakhshani

rakhshani@yahoo.com

Abolfazl Rad

rad6790@yahoo.com

1 Department of Obstetrics and Gynecology, Sabzevar University of Medical Sciences, Mobini Hospital, Sabzevar, Iran

2 Midwifery Department, Sabzevar University of Medical Sciences, Sabzevar, Iran

3 Department of Statistics, Faculty of Medicine, Sabzevar University of Medical Sciences, Sabzevar, Iran

4 Department of Biochemistry and Nutrition, Cellular and Molecular Research Center, Sabzevar University of Medical Sciences,

Sabzevar, Iran 